\title{
The Dundee coronary risk-disk for management of change in risk factors
}

\author{
Hugh Tunstall-Pedoe
}

\begin{abstract}
Objective-To devise a simplified system for grading and monitoring modifiable coronary risk in primary care, to be used with an action plan.

Methods - The risk equation came from 5203 men aged 40-59 in the United Kingdom heart disease prevention project, who had 331 coronary events over five years; the population rank (reading 1-100) was obtained by scoring 10359 participants in the Scottish heart health study. Calculation of rank was embodied in the Dundee coronary risk-disk; the formula was tested against the Whitehall study; disk and action plan were evaluated in primary care.

Results-The system measures modifiable coronary risk from smoking, blood pressure, and blood cholesterol concentration by a sex and age related rank running from 1 (high risk, priority action) to 100 (low risk, general advice). The formula predicted outcome acceptably in the Whitehall study and is built into a circular slide rule. Only eight $(11 \%)$ of 76 general practitioners and practice nurses surveyed already used risk factor scores. After evaluation most thought they should use one and proposed to incorporate the Dundee coronary risk-disk and the associated action plan into their routines.

Conclusion-The Dundee coronary risk-disk readout of Dundee rank, standardised on a scale of 1 to 100 by age and sex, is a simple, valid means of assessing and monitoring modifiable coronary risk. It puts single risk factors (such as cholesterol concentration) in perspective and can aid selective testing. Understood by medical staff and patients, it should improve the efficiency and effectiveness of the high risk approach to coronary prevention.
\end{abstract}

\section{Introduction}

In 1989 the Coronary Prevention Group and the British Heart Foundation convened a working group (chaired by Professor Geoffrey Rose) to draft an action plan for preventing coronary heart disease in primary care. They asked me to devise a new system for scoring risk factors to be used with it, a system that could be generally adopted as those currently available are not widely used.

The new system should apply to men and women aged 35 to 64; emphasise major modifiable risk factors; enter risk factor values directly; be compatible with selective cholesterol testing; relate to population distributions; and be based on published British data. This paper describes the Dundee score; its simplified derivative, the Dundee rank; the incorporation of score and rank into the Dundee coronary risk-disk; and the results of validation and evaluation in primary

Cardiovascular

Epidemiology Unit, Ninewells Hospital and Medical School, Dundee DD1 9SY

Hugh Tunstall-Pedoe, MD, director
Smoking habit, blood pressure, blood cholesterol concentration, and age were entered into the multiple logistic function, ${ }^{2}$ but subsequently age was set to 50 to generate a relative risk score confined to modifiable factors.

The Dundee rank was derived by calculating the Dundee score for each of the 10359 men and women aged 40-59 in the Scottish heart health study. ${ }^{3}$ The distribution by sex was defined in centiles and renamed Dundee rank, running from 1 (highest modifiable risk) to 100 (least modifiable risk). Dundee score and rank were re-examined in the Scottish MONICA population (aged 35-64), ${ }^{45}$ making adjustments for women.

The Dundee coronary risk-disk, a circular slide rule analogue of the multiple logistic function calculation for risk and rank was made; it consists of two disks and a pointer. Risk factors are entered from one disk and the resultant Dundee score and rank are read off the second.

Validation - The formula was used to predict deaths after five and 10 years in 15395 male civil servants aged 40-59 in the Whitehall study.

Testing in primary care-A draft of the action plan, the risk-disk and its manual, and a questionnaire were sent out to general practitioners and practice nurses for evaluation.

Results

DUNDEE SCORE AND RANK

The box shows a formula for the multiple logistic function with the modifications used for the Dundee system. The effects of age, smoking, blood pressure, and cholesterol concentration on coronary risk are all highly significant, and there is a gradient in risk with numbers of cigarettes smoked.

The distribution of the score was almost identical in men and women aged 40-59 in the Scottish heart health study (fig 1). In men the population distribution of score hardly changed with age in successive five year age groups. In women blood pressure and cholesterol concentration and therefore the Dundee score increased

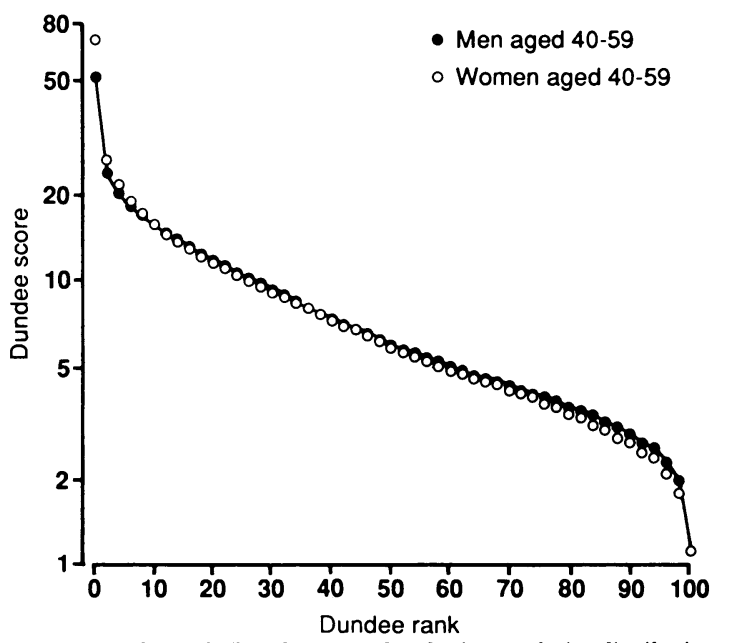

FIG 1-Dundee rank: Dundee score related to its population distribution in 10359 men and women
The Dundee score was based on the five year follow up for coronary mortality and non-fatal myocardial infarction (331 events) in 5203 men aged 40-59 in the United Kingdom heart disease prevention project. 


\section{Multiple logistic function formula and modifications}

Five year risk of coronary heart disease

$$
=\frac{1}{1+e^{-\left(a+b_{1} x_{1}+b_{2} x_{2}+b_{3} x_{3}+b_{4} x_{4}\right)}}
$$

Coefficients (SEs)

$\mathrm{a}=-10 \cdot 117(0.745)=$ constant $^{\star}$

$\mathrm{b}_{1}=0.06510(0.0114) \quad \mathrm{x}_{1}=$ age in years $\star$

$\mathrm{b}_{2}=0.010543(0.00270) \mathrm{x}_{2}=$ systolic blood pressure $(\mathrm{mm} \mathrm{Hg})$

$\mathrm{b}_{3}=0.009378(0.00131) \mathrm{x}_{3}=$ cholesterol $(\mathrm{mg} / 100 \mathrm{ml})^{\star \star}$

$\mathrm{b}_{4}=1.00 \quad \mathrm{x}_{4}=$ smoking code (see below) $)^{\star \star \star}$

Smoking codes

Never smoked $=\mathbf{0} \cdot \mathbf{0}$ (preset)

Ex-smoker or pipe or cigar smoker $=0 \cdot 1453(0.224)$

Cigarettes per day:
$1-9$
10
$=0.4483(0.274)$
$=0.9242(0.283)$
20
$=1.019(0.228)$
$=0.9333(0.247)$
$=1.263(0.303)$
$=1.431(0.285)$

Modifications for Dundee coronary risk-disk:

*Constant "a" reset for fixed age 50:

$-10.117+(50 \times 0.0651)=-6.8624$.

This value is constant for men but is modified in women by age:

$35=+0 \cdot 5719 ; 40=+0 \cdot 3875 ; 45=+0 \cdot 1922$;

$50=+0 \cdot 0156 ; 55=-0 \cdot 1047 ; 60=-0 \cdot 2219 ;$

$65=-0 \cdot 3156$

$\star \star$ Cholesterol:

$\mathrm{b}_{3}=0.3627 ; \mathrm{x}_{3}=\operatorname{cholesterol}(\mathrm{mmol} / \mathrm{l})$

$\star \star \star$ Cigarette dose-response rationalised to:

$1-4 /$ day $=0.406$

$5-9 /$ day $=0.406+($ No of cigarettes -5$)(0.0813)$

$10-29 /$ day $=0.8125+($ No of cigarettes -10$)(0.0312)$

$\geqslant 30 /$ day $=1.437$

TABLE I - Deaths from coronary causes after five and 10 years in 15395 male civil servants aged 40-59 by decile of Dundee score

\begin{tabular}{lcc}
\hline & \multicolumn{2}{c}{ No (\%) of deaths } \\
\cline { 2 - 3 } $\begin{array}{lc}\text { Decile of } \\
\text { Dundee score }\end{array}$ & $\begin{array}{c}\text { After 5 } \\
\text { years } \\
(\mathbf{n}=195)\end{array}$ & $\begin{array}{c}\text { After 10 } \\
\text { years } \\
(\mathbf{n}=510)\end{array}$ \\
\hline 1 & $8(4)$ & $18(4)$ \\
2 & $10(5)$ & $24(5)$ \\
3 & $13(7)$ & $33(6)$ \\
4 & $18(9)$ & $40(8)$ \\
5 & $21(11)$ & $42(8)$ \\
6 & $9(5)$ & $37(7)$ \\
7 & $16(8)$ & $52(10)$ \\
8 & $21(11)$ & $56(11)$ \\
9 & $29(15)$ & $84(16)$ \\
10 & $50(26)$ & $124(24)$ \\
\hline
\end{tabular}

with age. Before correction, the cut off point equivalent to rank 15 would produce $15 \%$ of men in each five year age group 40-59, whereas in women it would produce $15 \%$ overall, but twice as many women aged $55-59$ as 40-44. Score and rank are simpler if they have a constant relation across age and sex groups. The population data from the Scottish heart health study and Scottish MONICA project were used to adjust the scores for each age in women to give the best overall fit to figure 1 for ranks $10,15,20,25$, and 50 , the high risk end of the distribution; this was achieved by adjusting the multiple logistic function constant "a."

\section{DUNDEE CORONARY RISK-DISK}

Initially the "Dundee coronary risk-disk" was made and field tested as concentric card disks. The production version (fig 2) consists of two solid disks, back to back, with coloured scales and a wrap around pointer. The front disk is divided into segments for smoking, blood pressure, and cholesterol scales. The operator uses either the systolic or diastolic (phase V) blood pressure. A supplementary cholesterol scale shows mean British population levels by sex and age,? so that a provisional Dundee rank can be assigned while the operator considers whether cholesterol testing is warranted. The rear disk contains concentric scales for rank and score and the offsets by age for women. The risk factor scales on the front are linear but the score scale is almost logarithmic, reflecting multiplicative interaction of risk factors. Rank follows a normal or Gaussian distribution curve on the score scale (fig 1), being crowded in the middle ranges and spread out at the edges, where extreme scores are rare.

USE OF THE DISK

Except in women, for whom it is offset by age, the rear notch is aligned with the front one, the zero point for smoking habit. Risk factor values are entered in turn by rotating both disks together through the pointer by the appropriate amount, so that the rear disk is rotated incrementally, from least risk towards most risk, once for each risk factor. Blood pressure and cholesterol concentration cannot be entered until they have been zeroed on the pointer, which is done by rotating the front disk alone through the pointer, keeping the rear disk stationary. The sequence of rotations is therefore line up the disks, rotate both disks together, move front disk only, rotate disks together, move front disk only, rotate disks together, read out from rear disk and pointer-potentially confusing when first seen, but easily learnt and then self evident.
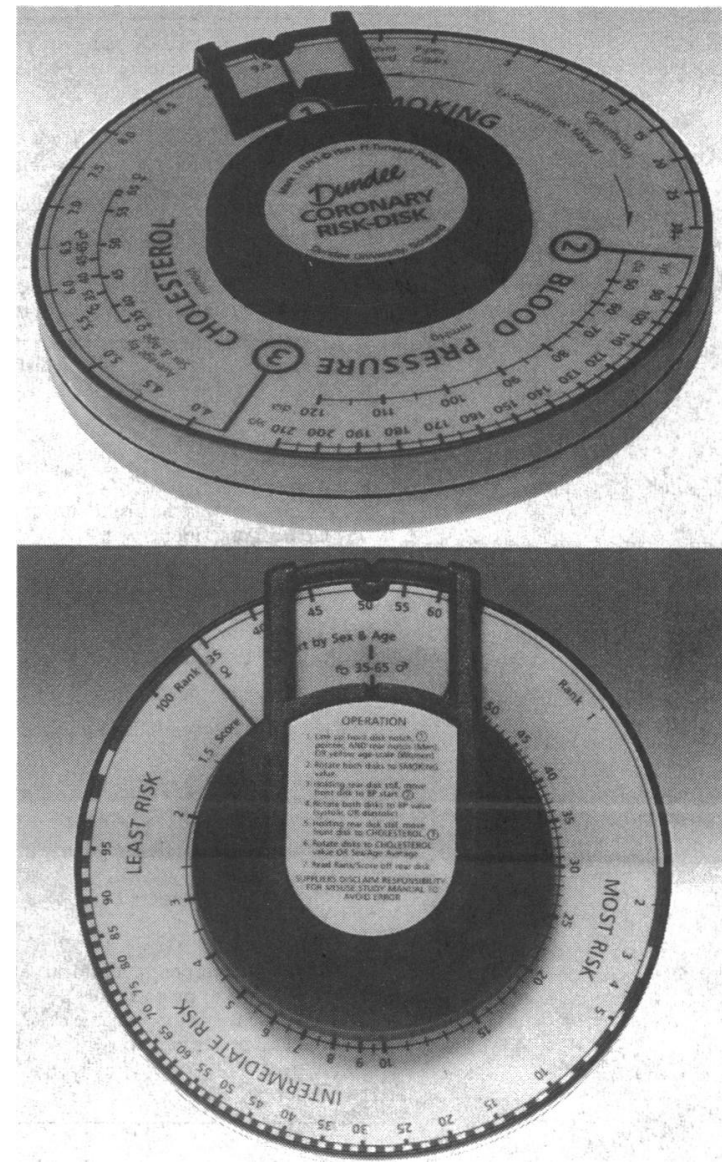

FIG 2-Front and rear views of Dundee coronary risk-disk

\section{VALIDATION}

Applied to the Whitehall study, the Dundee score produced the risk gradient shown in table I, placing in the top $20 \%$ of risk $41 \%$ of the 195 deaths from coronary heart disease after five years and $40 \%$ of the 510 deaths after 10 years. The relative risk of those in the top versus bottom decile of risk was 6.3 in five years and 6.9 in 10 years.

\section{TESTING IN PRIMARY CARE}

General practitioners (and their nurses) were recruited from a cardiology course in Newcastle and practice nurses (and their doctors) from their conference in Perth. The response from Newcastle produced 33 forms from practitioners and 12 from nurses; that from Perth produced 11 forms from doctors and 20 from nurses. After inability to participate was corrected for the response rate among Newcastle doctors was $85 \%$; the response from Perth was less complete. Results were similar and were combined in table II. Most respondents were carrying out risk factor assessment or were about to do so, but 
only $11 \%$ used a score. Most felt the need for a risk score and stated that they would incorporate the Dundee coronary risk-disk and the action plan into their practices when they became available. The action plan and risk-disk were generally welcomed, as was the manual (needed more badly for initiation and instruction by some than others; see table II). Many requested a solid disk and a professionally produced manual; these have now appeared. Several wanted additional risk factors included, but there was no consensus on which.

TABLE II-Results of evaluation of risk-disk and action plan in primary care. Responses were from 44 general practitioners and 32 practice nurses

\begin{tabular}{|c|c|c|c|c|}
\hline "Yes/no" questions & Yes & No & $\begin{array}{l}\text { No } \\
\text { answer }\end{array}$ & $\begin{array}{c}\text { Not } \\
\text { applicable }\end{array}$ \\
\hline \multicolumn{5}{|c|}{$\begin{array}{l}\text { Is your practice already using a risk } \\
\text { factor scoring system? }\end{array}$} \\
\hline General practitioners & \multirow{3}{*}{\multicolumn{2}{|c|}{$\begin{array}{cc}2 & 42 \\
6 & 22 \\
8(11) & 64(84)\end{array}$}} & & 0 \\
\hline Nurses & & & & 4 \\
\hline Total $(\%)$ & & & & $4(5)$ \\
\hline \multicolumn{5}{|c|}{ If no, do you think it should use one? } \\
\hline General practitioners & 28 & 2 & 12 & 2 \\
\hline Nurses & 16 & 0 & 6 & 10 \\
\hline Total (\%) & $44(58)$ & $2(3)$ & $18(24)$ & $12(16)$ \\
\hline \multicolumn{2}{|c|}{$\begin{array}{l}\text { "Circle degree of agreement" questions } \\
(5 \text { and } 4=\text { positive, } 2 \text { and } 1=\text { negative })\end{array}$} & 3 & 1 & No answer \\
\hline \multicolumn{5}{|c|}{$\begin{array}{l}\text { Does the Dundee coronary risk disk } \\
\text { impress you as a method of } \\
\text { assessing modifiable risk? }\end{array}$} \\
\hline General practitioners & 1523 & 4 & 1 & \\
\hline Nurses & 158 & 5 & & \\
\hline Total (\%) & $61(80)$ & $9(12)$ & $4(5)$ & $2(3)$ \\
\hline \multicolumn{5}{|c|}{ How difficult was the disk to use at first? } \\
\hline General practitioners & 211 & 15 & 9 & \\
\hline Nurses & 56 & 65 & & \\
\hline Total $(\%)$ & $24(32)$ & 2) $20(26)$ & $31(41)$ & $1(1)$ \\
\hline \multicolumn{5}{|c|}{$\begin{array}{l}\text { Were you happy to use it after } \\
\text { instruction? }\end{array}$} \\
\hline General practitioners & 339 & 0 & 1 & \\
\hline Nurses & 204 & 6 & & \\
\hline Total $(\%)$ & $66(87)$ & $6(8)$ & $2(3)$ & $2(2)$ \\
\hline \multicolumn{5}{|c|}{$\begin{array}{l}\text { Were you happy with the manual } \\
\text { of instructions? }\end{array}$} \\
\hline General practitioners & $21 \quad 12$ & 7 & 2 & \\
\hline Nurses & 214 & 5 & 20 & \\
\hline Total (\%) & $58(76)$ & f) $12(16)$ & $5(7)$ & $1(1)$ \\
\hline \multicolumn{5}{|c|}{$\begin{array}{l}\text { Would you use the disk regularly in } \\
\text { practice? }\end{array}$} \\
\hline General practitioners & $19 \quad 14$ & 6 & 2 & \\
\hline Nurses & & 5 & & \\
\hline Total $(\%)$ & $55(72)$ & 2) $11(14)$ & $8(11)$ & $2(3)$ \\
\hline \multicolumn{5}{|c|}{$\begin{array}{l}\text { Would you incorporate it into an } \\
\text { action plan or protocol for } \\
\text { identifying high modifiable risk? }\end{array}$} \\
\hline General practitioners & $23 \quad 11$ & 6 & 2 & \\
\hline Nurses & 204 & 2 & 13 & \\
\hline Total (\%) & $58(76)$ & $8(11)$ & $8(11)$ & $2(3)$ \\
\hline
\end{tabular}

\section{Discussion}

\section{NEED FOR A NEW SCORING SYSTEM}

A simple, valid, acceptable scoring system for coronary risk is needed for three reasons: to identify and help concentrate resources on those who will benefit most; to motivate change; and to provide a means for monitoring and reinforcing that change. Coronary risk is multifactorial, but most medical algorithms for risk factor management, while paying lip service to the others, consider them one at a time. ${ }^{89}$ Most high risk subjects, suffering from the multiplicative interaction of two or more moderately raised factors, are not so identified. Common experience and our own surveys show that earlier multifactorial scores - for example, from Framingham,${ }^{2}$ Minnesota, ${ }^{10}$ and the regional heart study ${ }^{11}$ - are not generally used.

\section{SCORING ABSOLUTE RISK}

Many earlier scores include unmodifiable factors such as age, sex, family history, previous vascular disease and current angina and diabetes along with modifiable factors to produce a score of absolute risk. Such scores are more accurate predictors than those restricted to modifiable factors, ${ }^{12}$ but the unmodifiable factors complicate the calculation and its interpretation and may be a hindrance to motivating the patient. Such scores in different age and sex groups are hard to interpret without knowing the distribution within these groups. The score from the regional heart study, ${ }^{11}$ with its sound pedigree, is valued for assessing men in life insurance terms, but some practitioners find it complex and pessimistic and would prefer a simpler tool for health promotion and follow up, one that is practical and motivational.

\section{RANKING RELATIVE MODIFIABLE RISK}

The Dundee system was designed to appeal to practitioners currently not using any score at all. Features new to the Dundee coronary risk-disk are the use of relative risk, applicable to different sex and age groups; the innovation of risk rank; restriction to the three major modifiable risk factors; incorporation into an action plan; provision of substitute cholesterol readings for selective testing; and a solid, two sided calculator.

The Dundee system incorporates the three classic modifiable factors and provides a measure either of relative risk or of ranking within the age and sex or disease peer group. Combination with the action plan for preventing coronary heart disease in primary care $^{13}$ exploits the concept of modifiable risk rank. The clinical risk group defined in the action plan identifies patients at high risk for medical reasons; the Dundee rank indentifies which of them have the greatest potential for change. Dundee rank is also used to set a cut off point in people free of disease, identifying need across age and sex groups.

Restricting the risk calculation to three factors is not to deny the importance of others relevant to intervention. Obesity hardly contributes to the multiple logistic function, but weight loss in obese patients is a potent method of influencing blood pressure and lipid concentrations. Exercise, difficult to measure (and not scored initially), is a means of losing weight and lowering risk. Alcohol figures in lifestyle counselling and in management of hypertension, but its relation to coronary risk is not straightforward.

The Dundee score performs acceptably against the Whitehall data, ${ }^{6}$ and the relative weightings attributed to the three factors are similar to those in many other studies. ${ }^{2}$ Validity is a matter for argument, but the acid test will be whether the Dundee coronary risk-disk is found useful. Should it achieve success it is conceivable that other factors might be added in future.

\section{SMOKING ATTRIBUTABLE RISK IN EX-SMOKERS}

In the United Kingdom heart disease prevention project ex-smokers ran a much lower risk than current smokers-over five years risk was not significantly higher than that in those who had never smoked. ${ }^{1}$ The regional heart study score measures smoking risk in "years of smoking" with slow change on stopping." The numbers of recent ex-smokers are limited in any study, so the decline curve is unclear. For the Dundee system a more motivational effect is proposed: risk reverses substantially but not immediately, following the declining path of other phenomena related to smoking, such as fibrinogen concentration, ${ }^{14}$ thus: within one year of stopping, no change in risk; between one and five years, divide the smoking risk attributable to previous cigarette consumption by number of years stopped; between five and 10 years, classify ex-smokers with pipe and cigar smokers (box); after 10 years, classify with never smokers.

\section{BLOOD PRESSURE}

The Dundee score is derived from the United Kingdom heart disease prevention project's multiple 
logistic function for systolic blood pressure. The project used diastolic phase IV readings, but phase V readings should now be standard in Britain, ${ }^{15}$ so those from the project have not been used. The diastolic equivalent for each systolic value is the reading that occurred most commonly opposite it in the Scottish heart health study. ${ }^{3}$ The risk-disk uses either systolic or phase $\mathrm{V}$ diastolic blood pressure.

\section{CHOLESTEROL AND SELECTIVE TESTING}

The argument for selective versus opportunistic testing for cholesterol concentration is well known. ${ }^{16}$ The action plan lists unifactorial indications for cholesterol testing. ${ }^{13}$ In other cases a provisional Dundee rank can be derived pending a decision on testing. The risk-disk can be used with any level of cholesterol testing. If a cholesterol result is available the Dundee rank places it in the context of overall modifiable risk.

The contribution of cholesterol measurement to the Dundee rank was tested in the Scottish heart health study population by correlating the provisional Dundee rank with the final one. Seventy per cent of subjects remained within the same risk decile or the one adjoining it.

\section{WOMEN}

The use of a relative risk score, together with the observation that risk factor distributions in men and women aged 40-59 are similar, means that the Dundee score and rank can be used for women as well as men. The weightings given to the three factors are derived from men. Absolute risk in women is lower, but despite the anomalous results on smoking from Framingham, ${ }^{2}$ the major risk factors seem to operate, and may be weighted similarly, in both sexes (unpublished data). Using the Dundee system for women is reasonable provided that users remember that score and rank are relative to that age and sex-a Dundee rank of 5 is far more threatening over five years to a man of 60 than to a woman of 40 . The offset by age in women is to ensure that equal proportions exceed preset cut off points. Altering the offset does not affect relative risk relations within an age group because the score is logarithmic.

\section{POTENTIAL FOR THE DUNDEE CORONARY RISK-DISK AND} DUNDEE RANK

Measurement of risk is not an end in itself but should be undertaken to improve patient management, to find those who stand to benefit most, and to motivate staff and patients. Otherwise the workload in risk factor counselling could be overwhelming. ${ }^{17}$

Current commercial interest in coronary risk is centred largely on lipids. There is a popular impression that cholesterol is all important and that coronary risk can be expressed in cholesterol units. The Dundee coronary risk-disk, through risk rank, has an educational role in putting cholesterol in perspective and emphasising interaction: cholesterol is not the only risk factor, and the risk attributable to a high reading depends on the levels of other factors. ${ }^{16}$

It may be ambitious to expect that the risk-disk will be adopted in most or even a substantial minority of practices assessing coronary risk factors. The adoption of a single standard would, however, have considerable advantages. Coronary risk could be discussed, measured, and tracked independently of any single risk factor. The Dundee rank has that potential: in classifying patients on a scale of 1 to 100 in terms of modifiable risk and, in lay terms, telling patients how far they are from the front of the coronary queue.

In addition to the members of the working group responsible for the action plan, I thank for help, ideas, and criticisms the doctors and nurses involved in formal and informal evaluations; Dr Simon Thompson and Mr Martin Shipley (London); Professor Gino Farchi and Dr Susanna Conti (Rome); the staff of Gerrard and Medd, designers (Edinburgh); the Coronary Prevention Group (London); and the cardiovascular epidemiology unit (Dundee). The Dundee unit is funded by the Scottish Home and Health Department; views expressed in this paper are my own. Financial help is acknowledged from a Toshiba Year of Invention award, the British Heart Eoundation, the Health Education Board for Scotland, and Dundee University.

The Dundee coronary risk-disk (UK registered design No 2011353 ) is supplied with an illustrated manual at a unit price of $£ 15$ (including VAT) plus $£ 3$ handling charge for each order (1-49 disks). An educational videocassette, software program, full price list, and further information are also available from: Risk-Disk, CVEU, Ninewells Hospital, Dundee DD1 9SY.

Potential users must be prepared to spend the time necessary for familiarisation and simple testing to prevent error; the suppliers disclaim responsibility for misuse in practice.

1 Rose G, Tunstall-Pedeo H, Heller RF. UK heart disease prevention project: incidence and mortality results. Lancet 1983;i:1062-5.

2 Chambless LE, Dobson A, Patterson CC, Raines B. On the use of a logistic risk score in predicting risk of coronary heart disease. Statistics in Medicine 1990;9:385-96.

3 Smith WCS, Tunstall-Pedoe H, Crombie IK, Tavendale R. Concomitants of excess coronary deaths - major risk factor and lifestyle findings from 10359 men and women in the Scottish heart health study. Scot Med J 1989;34: men and
$550-5$.

4 World Health Organisation MONICA Project Principal Investigators (Prepared by Tunstall-Pedoe $\mathbf{H}$ ). The World Health Organization Monica Project (Monitoring trends and determinants in cardiovascular disease): major international collaboration. F Clin Epidemiol 1988;41:105-14

5 Smith WCS, Shewry MC, Tunstall-Pedoe H, Crombie IK, Tavendale R. Cardiovascular disease in Edinburgh and north Glasgow-a tale of two cities. J Clin Epidemiol 1990;43:637-43.

6 Jarrett RJ, Shipley MJ, Rose G. Weight and mortality in the Whitehall study. BMF 1982;285:535-7.

7 Tunstall-Pedoe H, Smith WCS, Tavendale R. How-often-that-high graphs of serum cholesterol. Findings from the Scottish heart health and Scottish MONICA studies. Lancet 1989; i:540-2.

8 British Hypertension Society Working Party. Treating mild hypertension. $B M \mathcal{J}$ 1989;298:694-9.

9 European Atherosclerosis Society Study Group. Strategies for the prevention of coronary heart disease: a policy statement of the European Atherosclerosis of coronary heart disease: a policy state
Society. Eur Heart I 1987;8:77-88.

10 Thorsen RD, Jacobs DR, Grimm RH. Preventive cardiology in practice: a device for risk estimation and counselling in coronary disease. Prev Med 1979;8:548-56.

11 Shaper AG, Pocock SJ, Phillips AN, Walker M. A scoring system to identify men at high risk of a heart attack. Health Trends 1987;19:37-9.

12 Heller RF, Chinn S, Tunstall-Pedoe HD, Rose G. How well can we predict the development of coronary heart disease? Findings in the UK heart disease prevention project. BMF 1984;288:1409-11.

13 Coronary Prevention Group and British Heart Foundation. Action plan for preventing coronary heart disease in primary care. $B M \mathcal{F} 1991 ; 303: 748-50$.

14 Lee AJ, Smith WCS, Lowe GDO, Tunstall-Pedoe H. Plasma fibrinogen and coronary risk factors: the Scottish heart health study. $\mathcal{I}$ Clin Epidemiol 1990;43:913-9.

15 Petrie JG, O'Brien ET, Littler WA, de Swiet M. Recommendations on blood pressure measurement. $B M F$ 1986;293:611-5.

16 Tunstall-Pedoe $\mathrm{H}$. Who is for cholesterol testing? $B M J$ 1989;298:1593-4.

17 Imperial Cancer Research Fund OXCHECK Study Group. Prevalence of risk factors for heart disease in OXCHECK trial: implications for screening in primary care. $B M \mathcal{F}$ 1991;302:1057-60.

(Accepted 20 August 1991) 